\title{
La teoría del lenguaje del primer Romanticismo alemán y su repercusión en Nietzsche y Foucault ${ }^{1}$
}

\author{
ERNST BEHLER $(\dagger)$ \\ Universidad de Washington
}

1.

En la última parte de su libro Las palabras y las cosas, Foucault ha descrito con gran énfasis la honda ruptura epocal que, a su modo de ver, se ha producido en el mundo occidental con el paso del siglo XVIII al XIX. Se trata, dicho brevemente, de la quiebra del sistema clásico del racionalismo o de la Ilustración, con el que se estableció, por última vez en nuestra historia, un sistema meticulosamente construido y fiable de todo el saber humano. En palabras de Foucault, nuestro pensamiento abandonó entonces, hacia finales del siglo XVIII, «esos terrenos que habitaba antes» ${ }^{2}$. Se trató de un «acontecimiento radical», que se hizo manifiesto «sobre toda la superficie del saber» ${ }^{3}$. Sucedieron «alteraciones fundamentales» en cuantas «positividades» habían ocupado la época clásica ${ }^{4}$. Por «positividades» entiende Foucault objetos fundamentales de la investigación y de la orientación del mundo, que centran el interés de la humanidad durante cierto periodo de tiempo.

Foucault tiene una innegable predilección por las estructuras ternarias y los desarrollos tripartitos. De ahí que exponga también la ruptura epocal entre la Ilustración y el Romanticismo en tres ámbitos: en la economía política, en las ciencias naturales y en las ciencias humanas. El cambio fundamental provocado por esta transición a una nueva época se expresa, en primer lugar, en el uso de un nuevo vocabulario. Durante la era clásica, la economía política se expuso aún bajo el concepto de 'riqueza' y emprendió reflexiones sobre la riqueza y el comercio como situaciones de hecho objetivables; las ciencias naturales se

\footnotetext{
${ }^{1}$ Publicado originalmente con el título de «Die frühromantische Sprachtheorie und ihre Auswirkung auf Nietzsche und Foucault», Athenäum. Jahrbuch für Romantik, 11 (2001), 193 214 [Nota del traductor].

${ }^{2}$ Foucault, Michel, Las palabras y las cosas. Una arqueología de las ciencias humanas, Madrid: Siglo XXI, ${ }^{14} 1984$ (1968), p. 213.

${ }^{3}$ Ibid.

${ }^{4}$ Ibid., p. 216.
} 
caracterizaron por la tendencia a clasificar sus objetos y registrarlos en tablas, en un tableaux, como si de situaciones de hecho inalterables se tratara; y las ciencias humanas, por su parte, mostraron interés en el establecimiento de una gramática general que sirviera de base objetiva para el análisis del discurso. Esos objetos van a recibir ahora nuevos nombres. La riqueza se transforma en trabajo, por medio del cual se produce precisamente la riqueza; las tablas clasificatorias del siglo XVIII son reemplazadas por una ciencia de la vida, llamada biología, que se interesa por el devenir y las mutaciones de la vida, y trabaja con conceptos como 'organismo', 'unidad orgánica' u 'organicidad'; y la gramática general se sustituye por la filología y la lingüística, en particular por una lingüística comparativa, que investiga los elementos constitutivos del discurso y su cambio histórico. En relación con el lenguaje y el discurso, Foucault podría haber hecho referencia así mismo a los numerosos tratados que hacia finales del siglo XVIII aparecen con el título de Sobre el origen del lenguaje. Según Foucault, «ha sido necesario un acontecimiento fundamental -sin duda uno de los más radicales que se hayan presentado en la cultura occidental- para que se deshiciera la positividad del saber clásico y se constituyera una positividad de la que, sin duda, aún no hemos salido» ${ }^{5}$. Él habla de un momento histórico en el que surge «el ser mismo de nuestra modernidad». Se trataría, sin embargo, de un momento histórico que en gran parte se nos escapa, «porque aún estamos cogidos en su abertura ${ }^{6}$.

En cambio, a Foucault, que por lo demás nunca tuvo dificultades particularmente graves con las dataciones, no se le ha escapado dicho momento histórico y se atreve a ubicar ese acontecimiento entre las «fechas fácilmente asignables» de 1775 y 1825, esto es, en un periodo de unos 50 años, en el que se cuida de destacar incluso un núcleo de unos cinco años, entre 1795 y 1800, como nervio de todo el proceso ${ }^{7}$. Más adelante volveré a referirme a estas fechas. Pero antes, a fin de ofrecer una impresión del rápido cambio que entonces se efectuó, quisiera citar tan sólo el cambio tratado por Foucault en el ámbito de la economía política. Y es que, nada más comenzar con Adam Smith la reflexión sobre el concepto de trabajo, «de golpe, todos los viejos análisis de la moneda, del comercio y del cambio habrían sido relegados a una época prehistórica del saber» ${ }^{8}$. El trabajo se convirtió entonces en la medida del valor de cambio de todos los bienes 9 . Y otro tanto podría decirse del cambio en el ámbito de la historia natural, donde el concepto de 'vida' reemplazó a la taxonomía de las clasificaciones y la organización de los seres vivos respondió al concepto de trabajo prevaleciente en la economía. De manera análoga, se anuncian en el ámbito

\footnotetext{
${ }^{5}$ Ibid.

${ }^{6}$ Ibid.

${ }^{7}$ Ibid., p. 217.

${ }^{8}$ Ibid.

${ }^{9}$ Cf. ibid., p. 218.
} 
de la ciencia del lenguaje, con «la comparación horizontal entre las lenguas» ${ }^{10}$ que por entonces se hace notar, la irrupción de una gramática comparativa y la indagación, vinculada a ella, acerca de las raíces del lenguaje.

Lo que enseguida llama la atención en este desarrollo de una nueva episteme consiste en ese movimiento por el que el pensar se desprende de motivos objetivables y de su representación, y discurre hacia el devenir y la historia. El concepto capital de la Ilustración parece haber consistido en la 'representación': representación del orden objetivo de las $\cos ^{11}{ }^{11}$. Ahora, en cambio, la representación va a perder su poder de determinar el orden de las cosas en concordancia con el pensar y el saber. Un nuevo modelo de pensamiento hace su aparición, centrado en el desarrollo, la génesis y la pregunta por el origen. El punto de referencia se desplaza desde el mundo exterior y objetivable hasta el sujeto humano en cuanto condición de posibilidad de trabajo, vida y lenguaje. Pensar y saber se retiran del ámbito de la representación para explorar todo aquello que es fuente y origen de la representación ${ }^{12}$. Dicho en general, se produce una «retracción del saber [savoir] y del pensamiento [pensée] fuera del espacio de la representación» ${ }^{13}$, hasta aquello que es condición de posibilidad de la representación: poder de trabajo, fuerza de la vida y poder de hablar (o facultad del lenguaje). Con esta fórmula de 'condición de posibilidad', Foucault se está refiriendo naturalmente a Kant. Y de hecho añade: «La nueva positividad de las ciencias de la vida, del lenguaje y de la economía está en correspondencia con la instauración de una filosofía transcendental $»^{14}$. Trabajo, vida y lenguaje son transcendentales para Foucault, es decir, «están más allá del conocimiento» ${ }^{15}$. Con esta retracción al sujeto de trabajo, vida y lenguaje se abre el 'campo transcendental' de la subjetividad ${ }^{16}$.

Por lo que respecta al lenguaje, que es de lo que aquí se trata, según Foucault en aquella época se procura «inquietar las palabras que decimos»; «denunciar el pliegue gramatical» en el que nuestras ideas se han establecido; «disipar los mitos que animan nuestras palabras» ${ }^{17}$. La 'filología' hace su aparición «como análisis de lo que se dice en la profundidad del discurso» ${ }^{18}$. Para este análisis del lenguaje, Dios es «quizá menos un más allá del saber que un cierto más acá de nuestras frases» ${ }^{19}$-de acuerdo con el conocido diagnóstico de Nietzsche: «Temo

${ }^{10}$ Ibid., p. 229.

${ }^{11}$ Téngase en cuenta que la obra de Foucault, Les mots et les choses, se tradujo al alemán como Die Ordnung der Dinge, esto es, el orden de las cosas, que es a lo que hace referencia aquí Ernst Behler [Nota del traductor].

${ }^{12}$ Ibid., pp. 232ss.

${ }^{13}$ Ibid., p. 238.

${ }^{14}$ Ibid., p. 239.

${ }^{15}$ Ibid.

${ }^{16}$ Ibid.

${ }^{17}$ Ibid., p. 291.

${ }^{18}$ Ibid.

${ }^{19}$ Ibid., pp. 291-292. 
que no vamos a desembarazarnos de Dios porque continuamos creyendo en la gramática ${ }^{20}$. Foucault dice que nuestra interpretación, «en todo caso la que se formó en el siglo XIX, va de los hombres, de Dios, de los conocimientos o de las quimeras a las palabras que los hacen posibles; y lo que descubre no es la soberanía de un discurso primero, es el hecho de que nosotros estamos, antes aun de la menor palabra nuestra, dominados y transidos ya por el lenguaje ${ }^{21}$. Sea como fuere, añade, «el umbral del clasicismo a la modernidad [...] quedó definitivamente franqueado cuando las palabras dejaron de entrecruzarse con las representaciones y de cuadricular espontáneamente el conocimiento de las cosas» ${ }^{22}$.

Según Foucault, la reflexión filosófica se ha «mantenido alejada» durante mucho tiempo de este aspecto del lenguaje ${ }^{23}$. Incluso una vez que, con el paso del siglo XVIII al XIX, comenzara a ocuparse de este tema, tan sólo a finales del siglo XIX habría elevado el lenguaje al «campo del pensamiento» ${ }^{24}$. A lo que Foucault añade: «Y aun se podría decir que sólo en el XX, si el filólogo Nietzsche -que incluso allí era tan sabio, sabía tanto y escribía tan buenos libros- no hubiera sido el primero en acercar la tarea filosófica a una reflexión radical sobre el lenguaje» ${ }^{25}$. Esto mismo podría decirse, y con idéntica razón, de la reflexión sobre el lenguaje desarrollada por el primer Romanticismo alemán hacia finales del siglo XVIII. Con lo cual, Foucault parece haber perfilado con bastante exactitud el tema de mi conferencia, La teoría del lenguaje del primer Romanticismo alemán y su repercusión en Nietzsche y Foucault: el primer Romanticismo hacia finales del siglo XVIII, Nietzsche hacia finales del XIX y Foucault hacia finales del XX. Los cinco años, de 1795 a 1800, que Foucault señala como núcleo de ese proceso encajan, como anillo al dedo, con el periodo de la escuela protorromántica, formada en esa época en Jena. Claro que Foucault no ha tenido presente el primer Romanticismo alemán, del que tampoco sabía mucho ${ }^{26}$, sino que se refiere a la escuela filosófica de París, integrada por los así llamados 'Ideólogos' y Joseph-Marie de Gérando y Destutt de Tracy, quienes se esfuerzan asimismo en trazar una genealogía de

${ }^{20}$ GD: KSA V 78 (CI, ed. A. Sánchez Pascual, Madrid: Alianza, 1973, p. 49).

${ }^{21}$ Foucault, M., op. cit., p. 292.

${ }^{22}$ Ibid., p. 296.

${ }^{23}$ Ibid.

${ }^{24}$ Ibid., p. 297.

${ }^{25}$ Ibid. (traducción modificada por nosotros).

${ }^{26}$ Foucault cita ampliamente a Friedrich Schlegel en el capítulo que le dedica a Franz Bopp en su libro (op. cit., pp. 274-288). Se refiere allí, sin embargo, a un escrito de Schlegel de 1808 que se sale ampliamente del radio de la escuela protorromántica (1795-1800) y pertenece ya al campo de la ciencia del lenguaje. Véase Behler, Ernst, «Die Sprachtheorie in Friedrich Schlegels frühen Schriften», en Gawoll, Hans-Jürgen - Jamme, Christoph (ed), Idealismus mit Folgen. Die Epochenwelle um 1800 in Kunst und Geisteswissenschaften. Festschrift zum 65. Geburtstag von Otto Pöggeler, München: Wilhelm Fink, 1994, pp. 75-86. 
nuestras palabras, si bien desde una posición filosófica distinta, orientada por la filosofía sensualista de Locke y Condillac. Aquí, en cambio, la indagación debe dirigirse al primer Romanticismo alemán y debe procurar, de una manera cordial con Foucault, rellenar un vacío dejado en su libro.

2.

Tan pronto se aborda el primer Romanticismo alemán desde el punto de vista del lenguaje humano, se comprueba que éste no ha sido ningún tema pasajero de la reflexión protorromántica, sino que estaba vinculado de una manera fundamental con todo lo que ella comprendía -la poesía y las demás artes, la retórica, la filosofía, la formación cultural, la religión, la sociedad y también el republicanismo. Para entender este carácter universal que posee el lenguaje en la manera de ver protorromántica, hay que partir de la base de que la poesía ha sido el tema central de esta escuela y de que los primeros románticos alemanes cifraron su tarea más genuina en la averiguación de lo que constituye la poesía en sentido propio. Lo cual no quiere decir que la naturaleza de la poesía debiera desarrollarse en conexión con problemáticas más amplias, como por ejemplo una estética sistemática, una enciclopedia de todas las artes y ciencias, o una doctrina de las facultades humanas de entendimiento, voluntad, sentimiento y fantasía. Antes bien, de acuerdo con su impulso original, el pensar protorromántico consistió en una reflexión fundamental sobre la naturaleza de la poesía, en una investigación de la condición de posibilidad de la poesía. El hecho más fundamental que con ello se puso de relieve no consistió, sin embargo, en las reglas, normas y leyes que habían sido desarrolladas por el Clasicismo a partir de la Poética de Aristóteles, ni en el libre juego de imaginación y entendimiento que Kant había ofrecido como explicación de la producción artística. En la reflexión protorromántica, esos hechos resultan ya de carácter secundario y derivado, frente al fenómeno mucho más fundamental del lenguaje humano.

El primer texto en el que esto se expresa son las Cartas sobre poesía, métrica y lenguaje de August Wilhelm Schlegel, compuestas en 1795 para la revista Horen de Schiller ${ }^{27}$. La peculiar manera de proceder de Schlegel en el sentido de una reflexión fundamental se muestra ya desde su tratamiento del metro. Él trata de dejar atrás esas explicaciones, a su modo de ver superficiales, que hablan del metro como ayuda a la memoria y placer de lo recurrente, y así derivar la relación humana con el tempo de nuestra fisiología, fundarla en fenómenos como el ritmo cardíaco y la respiración. Frans Hemsterhuis, a quien Schlegel cita a este respecto, había considerado ya el sentido del tiempo

${ }^{27}$ Schlegel, A.W., Sämtliche Werke, ed. E. Böcking, Leipzig: Weidmann'sche Buchhandlung, 1846, vol. 7, pp. 98-154 (en adelante, SW seguido del número de volumen en romano y el número de página en arábico). 
como fundamental para el ser humano y había dicho: «La representación del tempo es quizá la primera de todas nuestras representaciones y precede incluso al nacimiento; pues parece que no se la debemos más que a los chorros de sangre que se suceden en la vecindad del oído ${ }^{28}$. Con lo cual, la disposición humana para el tempo nos introduce, como dice Schlegel, en el «laberinto de la fisiología y la psicología ${ }^{29}$. La teoría del lenguaje humano de Schlegel tiene un carácter similar y es resultado de una reflexión fundamental sobre los basamentos últimos de la poesía, sobre sus condiciones antropológicas de posibilidad. Estas Cartas se gestaron en Amsterdam, donde por entonces Schlegel tenía su residencia, muy lejos por tanto de la especulación idealista que estaba teniendo lugar en Alemania. En ellas se hace referencia, de un modo atípico para la formación teórica de entonces, a autores como Moritz, Herder y Hemsterhuis, es decir, a representantes de una línea sensualista. Llevado sin embargo por el desarrollo de su teoría del lenguaje, A.W. Schlegel rebasó considerablemente estas fuentes y se apoyó también en Rousseau, cuya teoría del lenguaje conocía no sólo a través del Discurso sobre la desigualdad, sino asimismo por su póstumo Ensayo sobre el origen de las lenguas; en Charles de Brosses, quien le proporcionó el modelo de una formación mecánica del lenguaje a partir de los sonidos animales, modelo que se puede considerar como la teoría sobre el desarrollo del lenguaje predominante en la era de la Ilustración; pero, de una manera especial, Schlegel se apoyó en Frans Hemsterhuis, sobre todo en su Carta sobre el hombre y sus relaciones. Además, se ocupó intensamente de las Conversaciones gramaticales de Klopstock, de Herder, de Hamann y podría decirse que del entero y extraordinariamente rico espectro de teorías lingüísticas de la Europa de finales del siglo XVIII, que con tanta claridad se alzaba ante sus ojos.

Sobre la base de estas diversas propuestas, Schlegel distinguió tres posibles teorías de la formación del lenguaje: el lenguaje ha surgido de la imitación de los objetos mediante signos y de la permanente corrección de los mismos; es resultado de los «tonos de la sensación»; o bien tiene su origen en ambos, en la imitación y en los tonos, en el entendimiento y en la sensibilidad ${ }^{30}$. En el caso de esa primera teoría de un desarrollo mecánico de los signos, se trata de la formación, sostenida en conexión con Locke y Condillac, de un sistema de signos en perpetuo perfeccionamiento, que abarca desde la primera marca con sentido dejada por el hombre hasta el más complejo lenguaje informático, sistema que ha sido el modelo de pensamiento predilecto de la Ilustración europea acerca de la formación del lenguaje. Por su parte, la derivación del lenguaje desde los 'tonos de la sensación' se remite a Herder, quien ya había visto el carácter tonal como un momento esencial del desarrollo del lenguaje y en ello

\footnotetext{
${ }^{28}$ SW VII 135.

${ }^{29}$ Ibid.

${ }^{30}$ SW VII 112.
} 
vislumbró la relación originaria entre lenguaje y poesía. Ahora bien, tampoco iríamos descaminados de ver aquí asimismo una referencia a Rousseau, que en el Discurso sobre la desigualdad había caracterizado el primer lenguaje del hombre como 'grito de la naturaleza' y en el Ensayo sobre el origen del lenguaje consideró las pasiones como la causa de las primeras palabras y las primeras lenguas como las propias del poeta. La tercera teoría es una vía intermedia entre estas dos posiciones extremas, entre racionalismo y sensualismo, seguida por muchos teóricos del lenguaje de la época, entre ellos el propio Hemsterhuis. Pues bien, la característica peculiar de la teoría del lenguaje de Schlegel consiste en que el margen de sensibilidad y sentimiento no se reduce a una primera época de 'sensibilidad bruta' y 'pasión indómita', que luego, con la marcha de la civilización y del desarrollo del lenguaje, sería paulatinamente eliminada o dejada atrás. Antes bien, Schlegel se aferra a este elemento sensible, sentimental y poético del lenguaje incluso para la instrucción en la más alta cientificidad. Esta presencia constante de lo poético-sensible en el lenguaje se muestra, con toda nitidez, en la siempre actual relación del hombre con la poesía ${ }^{31}$.

Schlegel denomina al lenguaje «la más asombrosa creación del poder humano de poetizar», el «gran poema, nunca completo, donde se expone a sí misma la naturaleza humana» ${ }^{32}$. El lenguaje aparece aquí como una suerte de protopoesía de la humanidad, una fuerza creadora originaria del espíritu humano, que subyace a todas las lenguas cultas y formadas, y representa nuestro primer contacto espontáneo con el mundo. El lenguaje es el medio general de entendimiento de la humanidad. No es un producto de la sola razón, sino una fuerza más amplia, de la que la razón es sólo una parte y que comprende igualmente a la fantasía. De él resultan las lenguas cultas y formadas, que, al ser elaboradas por el entendimiento, ganan en utilidad y precisión, mas al precio de perder en fuerza originaria. En el lenguaje de la ciencia apenas si queda ya rastro de ese lenguaje originario. De este modo, se presenta aquí el lenguaje, en efecto, casi como en la teoría de Condillac, como un «compendio que la naturaleza» oculta ${ }^{33}$. A.W. Schlegel deja de lado, por imposible de responder, la pregunta acerca del origen del lenguaje, que tiene para él el mismo significado incierto que aquélla otra que interroga por el origen de la poesía o por el estado originario del hombre ${ }^{34}$. A su juicio, cuando los teóricos se sirven de este modelo de pensamiento, lo hacen para exponer estados de cosas, sin querer relatar «el proceso efectivo de estos acontecimientos según tiempo, lugar y circunstancias». Es tan grande la distancia entre aquél estado originario y los documentos más antiguos de que disponemos, que sólo puede ser salvada mediante un salto mortal. Muchos se han atrevido a dar un salto semejante, pero han fracasado en el intento. Hay

\footnotetext{
${ }^{31}$ SW VII 105.

${ }^{32}$ SW VII 104.

${ }^{33}$ SW VII 105.

${ }^{34}$ SW VII 111.
} 
quien se ha entretenido con los «juegos de ingenio o pesadas cavilaciones de una cierta etimología filosófica», que «ni el minucioso explorador del lenguaje ni el filósofo sensato» admiten; o quien ha procurado derivar todas las lenguas de un mismo tronco común. Con ello, sin embargo, sólo se ha conseguido arrojar una sombra de sospecha sobre la teoría filosófica, la única que permite hablar de ese problema ${ }^{35}$. Con lo cual, Schlegel pasa a ocuparse directamente de su propia teoría del lenguaje. Experimentamos a diario, argumenta, que el hombre emplea signos de comunicación tanto para expresar sus sensaciones, como sus pensamientos ${ }^{36}$. Estos signos consisten «en la viva pronunciación y en los gestos». En los gestos habla el sentimiento y sabe cómo comunicarse inmediatamente. A la humanidad la vincula una ligazón cordial de simpatía, consistente en una inmediata receptividad y capacidad para la comunicación, más importante para nuestro entendimiento mutuo que todo lo que la razón pueda poner a nuestra disposición. Esta capacidad general de comunicación y entendimiento llega tan lejos, que comprende a cada niño, hombre de las regiones más remotas e incluso «de los siglos más remotos». Éste es el «auténtico lenguaje del género humano, eterno, universalmente válido». Este lenguaje constituye lo originario en todas las lenguas cultas y formadas ${ }^{37}$. Para aclarar esta conexión son necesarios, no obstante, ambos sistemas de filosofía del lenguaje mencionados, que desde luego se volverían falsos tan pronto como uno de ellos «afirmara su [propia] ley fundamental del lenguaje como la única, con exclusión de la otra» ${ }^{38}$.

Schlegel ilustra también la interacción de ambas fuerzas formativas del hombre con el «origen de la poesía», del que desde una perspectiva histórica sabemos tan poco como «de la génesis del lenguaje». Si ese lenguaje más antiguo fue «efectivamente obra de ambas disposiciones unificadamente activas de la naturaleza humana», entonces fue también «imagen y figura absolutamente fieles, acento absoluto de las pasiones». Esto se puede asegurar si, en concordancia con una vieja tradición, se caracteriza el lenguaje más antiguo como 'poesía y música', en el buen entendido de que no puede haberse tratado de una poesía y una música cultivadas a partir de meras leyes técnicas de la forma exterior $^{39}$. Antes bien, con ello se hace referencia al carácter originalmente tonal, rítmico, de parte a parte metafórico del lenguaje, en cuanto primero de nuestros órganos para el encuentro con el mundo. Para Schlegel esto depende, no obstante, de que esas esferas del lenguaje permanezcan siempre presentes y de que también nosotros mostremos nuestra alianza con ellas en el estadio de las lenguas cultas y formadas.

\footnotetext{
${ }^{35} \mathrm{Ibid}$.

${ }^{36}$ SW VII 113

${ }^{37}$ SW VII 114

${ }^{38}$ SW VII 118

${ }^{39} \mathrm{SW}$ VII 121 ss.
} 
Esta cualidad poética y metafórica siempre presente en el lenguaje humano puede precisarse con la idea schlegeliana sobre la conexión de la mitología con la poesía y el lenguaje. Ya desde la primera frase de sus Lecciones sobre la doctrina filosófica del arte de Jena se expresa dicha conexión. Dice así: «El mito es, como el lenguaje, un producto general, un producto necesario del poder humano de poetizar; en cierto modo, una protopoesía del género humano» ${ }^{40}$. La mitología es un «lenguaje figurativo de la razón y de la fantasía hermanada a ella». En ese sentido, la mitología es una poesía que se alza sobre la poesía originaria del lenguaje y, a su vez, sirve también de basamento en sentido específico a la poesía resultante de ella. Pero, independientemente de esta referencia directa a la ficción poética que de manera ejemplar se da en la mitología griega, el mitificar es un componente fundamental en la organización poética, mitológica y metafórica del espíritu humano. En este sentido, para Schlegel la mitología no pertenece a una fase temprana y pasada de la humanidad, sino que forma, como el lenguaje, un fenómeno concomitante esencial de lo humano, un principio estructural del espíritu humano. Como el lenguaje, la mitología puede sufrir una merma de fuerza y colorido durante el proceso de racionalización. Pero, aun en el estatus culto de la razón, el espíritu humano mitifica. Nuestro modo de experimentar el mundo tiene siempre una tendencia espontánea a mitificar, que se manifiesta en la transformación metafórica de todo aquello con lo que entramos en contacto. Esta tendencia no debería confundirse ni minimizarse, dice Schlegel, como una forma de expresión meramente alegórica para conceptos complejos, como la mera adición de una figura fantástica al concepto. Se trata, más bien, del mitificar como decorado fundamental de la naturaleza humana, sin el cual no sería posible en general una experiencia humana. Schlegel es de la opinión de que los resultados últimos de la física y de las demás ciencias naturales tienen también una tendencia mitificadora, o bien pueden convertirse en mitología ${ }^{41}$.

3.

Hasta ahora, se ha expuesto la teoría del lenguaje del primer Romanticismo alemán principalmente a partir de la obra de August Wilhelm Schlegel, al haber sido este autor quien, por primera vez y de una manera coherente, la desarrollara en una serie de cartas. No obstante, dicha teoría es válida también, bajo esta forma, para Friedrich Schlegel y Novalis, quienes expresan determinados aspectos de un modo más afilado y también más paradójico. Se podría decir que August Wilhelm Schlegel reflexiona más sobre aquello que es posible para nosotros

\footnotetext{
${ }^{40}$ Schlegel, A.W., Kritische Ausgabe der Vorlesungen, ed. E. Behler en colaboración con F. Jolles, Paderborn: F. Schöningh, 1989ss., vol. 1, p. 49.

${ }^{41}$ Véase a este propósito, sobre todo, las lecciones berlinesas de Schlegel de 1801-1802 Sobre las bellas artes y letras, en op. cit., vol. 1, pp. 440-460.
} 
gracias al lenguaje en cuanto medio de comunicación de carácter metafórico y sobre el entendimiento que con él se logra, mientras que las reflexiones de Friedrich Schlegel y Novalis se orientan más hacia allí donde se muestran los límites del lenguaje y de su capacidad de comunicación. Lo cual no significa que estas reflexiones tengan el más mínimo carácter nostálgico o melancólico. La idea de la cárcel del lenguaje era ajena a estos pensadores. Ellos habrían visto una cárcel del género humano, más bien, en un sistema cerrado del entender y el saber consumados. Schlegel alude a ello donde dice: «En verdad, os daría pavor si el mundo entero, como reclamáis, por una vez y en serio se volviera completamente inteligible ${ }^{42}$. Para ellos, de lo que se trata más bien es de una afirmación jovial de ese carácter del lenguaje como órgano de comunicación y entendimiento asignado al hombre, cuyos límites pueden transgredirse con holgura gracias a toda una serie de técnicas a su disposición, como los juegos de lenguaje, la ironía o la comunicación indirecta.

Un ejemplo particularmente interesante de esta modalidad de crítica del lenguaje reside en el fragmento de Novalis que lleva por título Monólog $o^{43}$. Aquí, con apenas unos pocos trazos sueltos, queda de manifiesto el carácter trapacero del lenguaje, que una y otra vez nos impide alcanzar precisamente aquello que con su ayuda queríamos lograr: una comunicación íntegra y ordenada de nuestras ideas. La gente supone de ordinario -así expone Novalis este argumento- que se refiere a las cosas cuando habla. Sin embargo, pasa por alto que el lenguaje sólo se preocupa de sí mismo y enseguida deja decir al orador las «mayores pamplinas y falsedades». Cuando, por el contrario, el hablante habla sin ninguna finalidad ni intención, por el mero hecho de hablar, dice con frecuencia las verdades más solemnes y originales. Mucha gente odia el lenguaje a causa de estas propiedades suyas, pero debería saber que lo mismo ocurre con el lenguaje que con una fórmula matemática. Ambos se construyen un mundo para sí mismos, juegan tan sólo consigo mismos, y precisamente por eso se refleja en ellos la extraña trama de relaciones de las cosas. Hasta este punto, el fragmento puede interpretarse como un ejercicio de escepticismo lingüístico. Sin embargo, en este mismo lugar, Novalis le imprime un giro al curso de su pensamiento y pasa a concentrarse en las grandes capacidades de nuestro lenguaje. Pues sería justamente en ese hablar no intencional e inadvertido en lo que consiste la esencia de la poesía. Un escritor sería, al fin y al cabo, «tan sólo un poseso del lenguaje».

${ }^{42}$ Schlegel, F., Kritische Friedrich Schlegel Ausgabe, ed. E. Behler en colaboración con J.-J. Anstett (†), H. Eichner y otros expertos, Paderborn: Ferdinand Schöningh, 1958ss., vol. 2, p. 370 (en adelante, la sigla KFS seguido del número de volumen en romano y del número de página en arábico).

${ }^{43}$ Novalis, Novalis Schriften. Die Werke Friedrich von Hardenbergs, ed. R. Samuel en colaboración con H.-J. Mähl y G. Schulz, Stuttgart, 1960-1988, vol. 1, pp. 672-673. 
Para lograr una completa comprensión del mundo y mejorar nuestras facultades intelectuales -argumenta Friedrich Schlegel con sarcasmo-, nada hay más necesario que un 'lenguaje real'. Christoph Girtanner, un contemporáneo suyo de Göttingen dado a la poligrafía, había pronosticado el hallazgo de un lenguaje real para el entonces naciente siglo XIX, y lo había vinculado nada menos que a la promesa de que en ese mismo siglo se podría «fabricar oro» ${ }^{44}$. Schlegel nos asegura que él mismo siempre se había «asombrado en silencio de la objetividad del oro». Al fin y al cabo, hay oro por doquier en el mundo, donde sin embargo escasean la cultura y la ilustración, comprensiblemente, y a causa del oro todo sobra. Si también el artista dispusiera de la suficiente cantidad de esta materia, podría escribir obras en bajorrelieve, con letras de oro

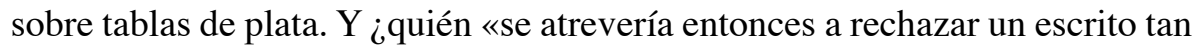
bellamente impreso con la grosera excusa de que resulta ininteligible»? «La única pena es que Girtanner ha muerto y el siglo XIX está ya en sus albores, sin que sus predicciones se hayan cumplido. Así que continúan las lamentaciones sobre nuestra ininteligibilidad y nuestra limitación lingüística ${ }^{45}$. Pero, ¿en verdad es la ininteligibilidad algo tan malo, tan abominable? -se pregunta Schlegel. Y responde: «Me da la impresión de que el bienestar de las familias y las naciones depende de ella; y, si no me engaño del todo, también el de Estados y sistemas, las obras de arte del hombre» ${ }^{46}$. A menudo, basta con una pequeña porción de verdad y certeza para poder producir dichos sistemas, con tal de que no se la ponga a prueba. «Sí, lo más preciado que tiene el hombre, su íntima satisfacción misma, pende en última instancia, como cualquiera puede saber fácilmente, de un punto tal, que debe quedar a oscuras, pues sólo por eso sostiene y soporta también el todo, y esa fuerza se perdería en el preciso instante en que se la quisiera disolver en el entendimiento» ${ }^{47}$. Dándole la vuelta, este pensamiento diría: «De todas formas, las más altas verdades de ese tipo son altamente triviales. Justamente por eso nada es más necesario que expresarlas siempre de nuevo y, en lo posible, de un modo cada vez más paradójico. Con ello no se olvidará que todavía están ahí y que, sin embargo, propiamente nunca se las puede dar a entender del todo ${ }^{48}$.

Como en el caso de Novalis, en estas formulaciones caprichosas se expresa una disciplinada y rigurosa reflexión sobre el lenguaje, un escepticismo lingüístico que no es sin embargo absoluto, sino que se trata de un escepticismo que, como dice el propio Schlegel, es tan antiguo como la filosofía misma. La forma de comunicación que corresponde a este tipo de lenguaje es, como en Novalis, la de un decir y un escribir indirectos. El tipo de decir y escribir

\footnotetext{
${ }^{44}$ KFS II 365.

${ }^{45}$ Ibid.

${ }^{46}$ KFS II 370.

${ }^{47}$ Ibid.

${ }^{48}$ KFS II 366.
} 
correspondiente al mundo de la inteligibilidad general, en el que no nos encontramos, sería el sistemático. El tipo de decir y escribir correspondiente al mundo de la ininteligibilidad, que es el nuestro, es el fragmento, el aforismo, la ironía, el diálogo, la comunicación pluralista. Es éste un pensar, un decir y un escribir que no está subordinado a una conexión de orden superior, porque ésta siempre se queda corta y sólo nos encorsetaría, aún más, en los límites del lenguaje. Este pensar, decir y escribir se exterioriza más bien a trozos, dialógicamente, fragmentariamente, y va siempre acompañado de una falta de entendimiento positiva, es decir, de una conciencia de la falta de entendimiento. En esta aparente imperfección del pensar, del decir y del escribir se exterioriza justamente la perfectibilidad del hombre.

Nietzsche va a adherirse directamente, en un momento decisivo para su propia formación, a esta teoría del lenguaje, e incluso podría decirse, sin exagerar, que el sustrato de su propia crítica de la razón y de toda filosofía que se quiera absoluta es resultado directo de esta relación. Se trata de la época inmediatamente posterior a la aparición de El nacimiento de la tragedia, cuando Nietzsche, en el contexto de una lección pronunciada en Basilea sobre la retórica griega, comenzó a ocuparse del fenómeno del lenguaje y, con ese fin, estudió también la teoría romántica del lenguaje, sobre todo en la exposición que hace Gustav Gerber en El lenguaje como arte. El escrito de Nietzsche Sobre verdad y mentira en sentido extramoral de 1873 es un precipitado directo de ese estudio ${ }^{49}$.

En este escrito, Nietzsche pretende mostrar, de manera crítica, «hasta qué punto el intelecto humano constituye, en la naturaleza, una excepción lamentable, vaga, fugitiva, inútil y arbitraria ${ }^{50}$. Con un estilo argumental sobrecargado de imágenes impactantes, Nietzsche describe cómo el ojo del hombre, «profundamente inmerso en ilusiones y en imágenes oníricas, [...] se limita a resbalar sobre la superficie de las cosas» $\mathrm{y}$ «se contenta con recibir estímulos y jugar a tantear sobre el dorso de las cosas ${ }^{51}$. La naturaleza le oculta al hombre la mayoría de las cosas, incluso las relativas a sí mismo y su propio cuerpo. ¿Qué es entonces lo que sabe, cuando habla, altivo, de autoconciencia, «de los repliegues de las vísceras, de la rápida corriente de la sangre, de las complejas

${ }^{49}$ Cf. Meijers, A. - Stingelin, M., «Konkordanz zu den wörtlichen Abschriften und übernahmen von Beispielen und Zitaten aus Gustav Gerber: Die Sprache als Kunst (Bromberg 1871) in Nietzsches Rhetorik-Vorlesungen und in Über Wahrheit und Lüge im außermoralischen Sinne», Nietzsche-Studien, 17 (1998), 350-368.

${ }^{50}$ KSA I 875ss. (El libro del filósofo, ed. A. Berasain, Madrid: Taurus, 1974, p. 85). Fue Lacoue-Labarthe, en un artículo publicado en 1971 en el número 5 de la revista Poétique con el título de «Le détour (Nietzsche et la rhétorique)» (pp. 99-142), el primero en llamar la atención sobre la conexión entre la teoría del lenguaje de Nietzsche y la del primer Romanticismo alemán.

${ }^{51}$ KSA I 876 (El libro del filósofo, pp. 86-87, modificada por nosotros). 
vibraciones de las fibras» en su propio cuerpo $?^{52}$ La naturaleza lo encerró «en una conciencia altiva y quimérica» - y a continuación tiró las llaves ${ }^{53}$. Si «por una vez quisiera mirar, a través de una hendidura, lejos del cuarto de la conciencia», se percataría entonces de que «el hombre se apoya en la inmisericordia, en la avidez, en la insaciabilidad, en el asesinato, en medio de la indiferencia de su ignorar, pendiente en sueños sobre el lomo de un tigre» ${ }^{54}$. Sólo en virtud de su capacidad de olvido pudo el hombre formarse la idea ilusoria de estar en posesión de la verdad. Pues las «convenciones del lenguaje» son poco más que «testimonios del conocimiento» ${ }^{55}$; no «designaciones» congruentes de las cosas, ni «expresión adecuada de todas las realidades», sino más bien «ilusiones», «cáscaras vacías» ${ }^{56}$. Sólo la convención, no la verdad, ha sido decisiva para el origen del lenguaje. Ni siquiera tenemos autoridad para decir, por ejemplo, «la piedra es dura», pues sólo conocemos lo «duro» como «una excitación totalmente subjetiva» ${ }^{57}$. Ni poseemos tampoco una base objetiva para clasificar las cosas en función de su género, para designar el árbol como masculino y la planta como femenina; o para hablar de la serpiente, cuya denominación como «lo que se retuerce» podría aplicarse igualmente al gusano ${ }^{58}$. De compararlos entre sí-argumenta Nietzsche-, los distintos lenguajes mostrarían «que con las palabras nunca se llega a la verdad, nunca a una expresión adecuada» ${ }^{59}$. La 'cosa en sî́ le resulta completamente indiferente a aquél que le da forma al lenguaje. Éste designa, más bien, «las relaciones de las cosas para con el hombre y para expresarlas acude a las metáforas más audaces ${ }^{60}$.

Como queda claro a partir de estos argumentos, la crítica lingüística de Nietzsche es prioritariamente una crítica del lenguaje de la filosofía y de las pretensiones de verdad que habitualmente lleva aparejadas. Lo que la vincula más directamente a la teoría del lenguaje del primer Romanticismo alemán es su acentuación del carácter creativo, artístico, poético y metafórico del lenguaje, su concepto del lenguaje como arte. «Por tanto, ¿qué es la verdad?»-se pregunta Nietzsche-; y responde: «Una multitud en movimiento de metáforas, metonimias, antropomorfismos; en una palabra, un conjunto de relaciones humanas que, elevadas, traspuestas y adornadas poética y retóricamente, tras largo uso el pueblo considera firmes, canónicas y vinculantes: las verdades son ilusiones de las que se ha olvidado que lo son, metáforas ya usadas que han perdido su fuerza sensible, monedas que han perdido su imagen y que ahora sólo entran

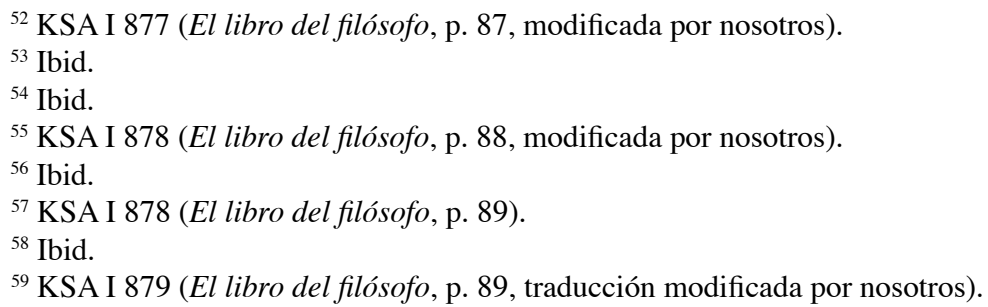


en consideración como metal, no como tales monedas $»^{61}$. Un investigador que operase sobre la base de ese lenguaje, en rigor, tan sólo reconocería «la metamorfosis del mundo en los hombres $»^{62}$. Su actuación se asemejaría a la del astrólogo, «que consideraba las estrellas al servicio de los hombres y en conexión con su dicha y con su dolor» ${ }^{63}$. A sus ojos, «el mundo entero está vinculado a los hombres, como el eco infinitamente sostenido de un sonido original: el hombre, como la imagen reproducida de una imagen arquetípica: el hombre ${ }^{64}$. Ese investigador cree tener las «cosas inmediatamente ante sí, como puros objetos» y en consecuencia olvida «las metáforas originarias de la intuición en cuanto tales metáforas». ${ }^{65}$ Sólo por eso, «por olvidarse en tanto que sujeto y precisamente en cuanto sujeto que crea artísticamente», puede tener lugar la cientificidad en el sentido de verdad filosófica ${ }^{66}$. Sin embargo, tan pronto como el hombre «pudiera salir por un instante de los muros de la cárcel de esta creencia», le habría llegado su hora tanto a esta pretensión de cientificidad, como a su autoconciencia ${ }^{67}$.

5.

La lectura de Sobre verdad y mentira debe interrumpirse aquí, al haber quedado lo suficientemente expresada en las secciones de este texto tratadas hasta el momento la crítica nietzscheana del lenguaje. En lo esencial, dicha crítica consiste en que nuestro lenguaje es ciertamente un asombroso órgano de comunicación interhumano, pero resulta inadecuado para la filosofía y la ciencia, es decir, para la comunicación de estados de cosas objetivos. Naturalmente, en este punto salta al instante la pregunta dirigida a Nietzsche acerca de cómo cabe entonces comunicar ideas a través de ese lenguaje -y por cierto que ya no sólo en un sentido general, sino sobre todo en un sentido defendido por el propio Nietzsche. Pues el caso es que, aun después de habérsele revelado la ineptitud de nuestro lenguaje para el conocimiento y la comunicación de estados de cosas objetivos, no por eso dejó Nietzsche de hablar y escribir, sino que siguió articulando un pensamiento tras otro y escribiendo un libro detrás de otro. En rigor, sin embargo, sobre la base de esa teoría del lenguaje Nietzsche no habría podido escribir un texto como Sobre verdad y mentira. Cuando relata en este escrito la transformación de una excitación nerviosa en un sonido articulado, de un sonido en una palabra, de una palabra en un concepto, Nietzsche está

${ }^{60}$ Ibid.

${ }^{61}$ KSA I 880-881 (El libro del filósofo, p. 91, traducción modificada por nosotros).

${ }^{62}$ KSA I 883 (El libro del filósofo, pp. 93-94).

${ }^{63}$ KSA I 883 (El libro del filósofo, p. 94, traducción modificada por nosotros).

${ }^{64}$ Ibid.

${ }^{65}$ Ibid. (traducción modificada por nosotros).

${ }^{66}$ Ibid. (traducción modificada por nosotros). 
ya formulando enunciados objetivos sobre cosas, sobre la base incluso de una teoría del origen abundante en presuposiciones. De acuerdo con los enunciados de ese escrito, ni siquiera podemos echar un vistazo fuera de nuestro angosto cuarto de la conciencia, porque la naturaleza, tras encarcelarnos allí, ha tirado las llaves. Pero el propio Nietzsche bien que mira fuera de este cuarto y nos cuenta que allí imperan la inmisericordia, la avidez, la insaciabilidad y el asesinato, y nosotros pendemos, en nuestra ignorancia, sobre el lomo de un tigre. La crítica del lenguaje debe eliminar la creencia en un mundo de objetos fuera de nuestra conciencia. Sin embargo, Nietzsche emplea al mismo tiempo este mundo de objetos como criterio del fracaso de nuestro lenguaje. Con lo cual, apuntala eso mismo que quiere refutar. No obstante, Nietzsche no debe ser acusado por ello de enredarse en contradicciones, ya que pudo ser perfectamente consciente de las consecuencias de su escrito y es posible que incluso fueran deliberadas. Antes bien, estas observaciones críticas apuntan a la pregunta más fundamental acerca de qué reglas, qué orden ha seguido Nietzsche para organizar su discurso; qué valor enunciativo tiene su escrito y cómo debe ser interpretado por nosotros ${ }^{68}$.

A lo cual hay que responder, antes de nada, que de ningún modo puede sobrevalorarse la significación para su pensamiento posterior y nuestro entendimiento del mismo de la teoría del lenguaje que Nietzsche ha desplegado en el escrito Sobre verdad y mentira. Los análisis de crítica lingüística de este texto habían llevado al convencimiento de que el lenguaje no permite decidir nada con relación a la naturaleza de las cosas y de que con él nos encontramos simplemente en el mundo del hombre. En adelante, sin embargo, Nietzsche va a transformar estas consideraciones críticas en un discurso más amplio de crítica de la metafísica. Una de estas transformaciones de que hablamos se encuentra ya en el aforismo 39 de Humano, demasiado humano, donde dice: «Primero se llama buenas o malas a acciones aisladas sin tomar para nada en cuenta sus motivos, sino únicamente por las consecuencias útiles o nocivas. Pero no tarda en olvidarse el origen de esos calificativos y se imagina que la propiedad "bueno" o "malo" es inherente a los actos en sí, sin tener en cuenta sus consecuencias, con lo cual se comete el mismo error por el que el lenguaje califica a la piedra misma de dura, al árbol mismo de verde, tomando por tanto como causa lo que es efecto» ${ }^{69}$. Aquí, la referencia a su crítica temprana del lenguaje es inmediatamente visible aún en la elección de los ejemplos ('piedra dura', 'árbol verde'), procedentes ambos de Gerber. El aforismo 121 de La gaya ciencia expresa una idea similar, en la que sin embargo la referencia a su crítica lingüística de juventud ya no se deja reconocer directamente. Reza así: «Nos

${ }^{67}$ KSA I 883-884 (El libro del filósofo, p. 94, traducción modificada por nosotros).

${ }^{68}$ Cf. Behler, E., «Nietzsches Sprachtheorie und der Aussagecharakter seiner Schriften», Nietzsche-Studien, 25 (1996), 64-86. 
hemos fabricado un mundo en el que podemos vivir - suponiendo cuerpos, líneas, planos, causas y efectos, movimiento y reposo, forma y contenido: isin estos artículos de fe no hay quien pueda vivir ahora! Pero no por ello son algo demostrado. La vida no es un argumento; entre las premisas de la vida bien pudiera figurar el error» ${ }^{70}$.

Esta transformación de su crítica temprana del lenguaje en una crítica de rango superior se refleja también en el hecho de que Nietzsche la refiera a otros territorios estrechamente vinculados al lenguaje, como la conciencia, la razón, la capacidad de comunicación y la gramática ${ }^{71}$. El tema de la gramática tiene, a este respecto, una especial significación. Ahora bien, no debe entenderse la gramática en un sentido técnico, lingüístico, sino como «el dominio y la dirección inconscientes ejercidos a través de funciones gramaticales idénticas» por pueblos pertenecientes al mismo tronco lingüístico, ya como 'atavismo'-según explica Nietzsche en el aforismo 20 de Más allá del bien y del mal-, ya como condicionante fisiológico previo de nuestra aproximación al mundo: «el hechizo de determinadas funciones gramaticales es, en definitiva, el hechizo de juicios de valor fisiológicos y de condiciones raciales» ${ }^{72}$. En el Prólogo de este escrito, Nietzsche había tenido ya en cuenta la «seducción por parte de la gramática» como posible fundamento para la génesis de sistemas filosóficos ${ }^{73}$. Luego, en el aforismo 34 del mismo escrito, acentúa aún más el carácter sobrevenido, casual y perspectivístico de la gramática, e incluso se mofa de su malentender como certeza inmediata. Compara allí la «credulidad en la gramática» con la creencia en «gobernantes», y se pregunta: «Mas ¿no sería hora de que la filosofía abjurase de la creencia en los gobernantes? ${ }^{74}$.

Estas ideas encuentran respuesta en los fragmentos inéditos de Nietzsche. Aquí se hace responsable al lenguaje de que «sobreinterpretamos disonancias y problemas en las cosas, porque sólo pensamos en forma lingüística» y, en cambio, «dejamos de pensar, cuando queremos hacerlo sin violentar el lenguaje» ${ }^{75}$. Estas reflexiones conducen a Nietzsche al enunciado tantas veces citado de $« E l$ pensar racional es un interpretar según un esquema, del que no nos podemos desprender» ${ }^{76}$. Que Nietzsche está pensando al unísono lenguaje, gramática y razón se muestra, con tenso esfuerzo, en la crítica de la razón de Crepúsculo de los ídolos ${ }^{77}$. Aquí se dice a propósito del lenguaje que, con la pregunta sobre

${ }^{69}$ KSA II 62 (HH, tr. A. Brotons Muñoz, Madrid: Akal, 1996, I, pp. 67-68).

${ }^{70}$ KSA III 477-478 (GC, tr. C. Crego y G. Groot, Madrid: Akal, 1988, p. 158).

${ }^{71}$ Behler, E., op. cit.

${ }^{72}$ KSA V 34-35 (MBM, tr. A. Sánchez Pascual, Madrid: Alianza, 1983, p. 42, modificada por nosotros).

${ }^{73}$ KSA V 11-12 (MBM p. 18, modificada por nosotros).

${ }^{74}$ KSA V 52-54 (MBM p. 61, modificada por nosotros).

${ }^{75}$ KSA XII 193.

${ }^{76}$ KSA XII 194. 
su génesis, entramos en «la época de la forma más rudimentaria de psicología» e incurrimos en un «fetichismo grosero cuando adquirimos consciencia de los presupuestos básicos de la metafísica del lenguaje, dicho con claridad: de la razón» ${ }^{78}$. Nietzsche llega allí a la siguiente conclusión: «La razón en el lenguaje: ¡oh, qué vieja hembra engañadora! Temo que no vamos a desembarazarnos de Dios porque continuamos creyendo en la gramática...» ${ }^{79}$. La teoría del lenguaje como punto de partida del pensar nos introduce, por lo tanto, bien lejos y bien a fondo en el universo de ideas de Nietzsche, e impregna el conjunto de sus escritos. Desde el punto de vista de la constitución del hombre, el lenguaje es la condición más fundamental de todo contacto con el mundo, la primera de toda 'condición de posibilidad', por decirlo en terminología kantiana, o de toda 'necesidad fisiológica', por emplear el propio vocabulario de Nietzsche ${ }^{80}$. El aforismo 119 de Aurora parece particularmente revelador a este respecto. Lleva por título Vivenciar y poetizar ${ }^{81}$ y en él se comparan nuestros estados de vigilia con los de sueño. En ambos casos, reaccionamos a excitaciones procedentes de la naturaleza exterior y las trasladamos a nuestro mundo humano. Aun así, eso será más palpable en los sueños, pues los estímulos se dejan determinar mejor por ellos: «movimientos de la sangre y de las vísceras» - «presión del brazo y de las mantas» - «sonidos de los campanarios, de las veletas, de los insomnes y otras cosas por el estilo» ${ }^{82}$. La 'razón poética' se imagina causas para estas excitaciones -ése es el caso tanto en el sueño como en la vida consciente-. Pero en el estado de vigilia no se tiene la misma libertad de interpretación que en el de sueño. Quizá, dice Nietzsche, «nuestra así llamada conciencia no sea sino un comentario más o menos fantástico de un texto inconsciente, quizá indescifrable, pero sentido» ${ }^{83}$. O, todavía en el mismo aforismo 119 , pregunta con aún mayor radicalidad: «¿Qué son, pues, nuestras vivencias? ¡Mucho más lo que ponemos en ellas que lo que hay en ellas! ¿O habría que decir: no hay nada en sí? Vivenciar es un fingir poético» ${ }^{84}$.

En este sentido, Nietzsche ha permanecido fiel a la visión alcanzada en Sobre verdad y mentira de que no podemos efectuar ningún conocimiento objetivo, sino únicamente registrar nuestras propias impresiones y reacciones. Esto sería lo que él mismo ha hecho en sus escritos, al darle cauce expresivo, de una manera más radical de lo que ningún otro escritor se haya atrevido nunca, a su propio personaje, a sus enfermedades y sus momentos de felicidad, al lugar de redacción de sus textos, a sus propios deseos de año nuevo e incluso a sus

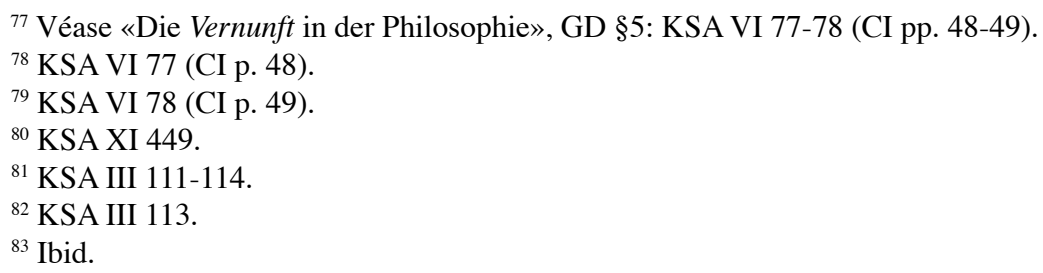


predilecciones culinarias. Lo que él expone son acontecimientos que tienen repercusiones de antemano o de los que todavía se derivan repercusiones incluso mucho después de haber ocurrido; procesos que todavía perduran y que presumiblemente perdurarán por siempre; ideas que en el momento de su redacción se volatilizan; y actos de autoconocimiento que no tienen éxito, porque estamos demasiado distantes de nosotros mismos. En todo caso, ningún hecho constatable, sino conjeturas que no se dejan demostrar y para cuya comunicación resulta inadecuado el lenguaje de la ciencia y de la filosofía tradicional. Pues estos fenómenos sólo se dejan comunicar en un lenguaje que insinúe mediante imágenes y trate de persuadir con su sonido -en el lenguaje de la retórica. Este lenguaje de la retórica depende consustancialmente, sin embargo, de un oyente, cuya aprobación no sólo recaba con todos los medios del arte oratoria a su alcance, sino al que también conmueve con las figuras de la provocación, el impacto, la invectiva y la maledicencia. Éste parece ser el carácter enunciativo de los escritos de Nietzsche, que proviene inmediatamente de su teoría del lenguaje. En estos textos, la búsqueda de las condiciones de posibilidad de nuestra experiencia del mundo se concentra en una autocrítica del pensar y de la filosofía. Con una investigación más minuciosa, se comprueba que ésta autocrítica tiene un sustrato teórico-lingüístico o crítico-lingüístico.

6.

Foucault había sostenido el punto de vista de que «sólo a finales del siglo XIX ha entrado el lenguaje directamente y por sí mismo en el territorio del pensamiento» ${ }^{85}$, es decir, una vez que hacia finales del siglo XVIII la escuela proto-romántica lo pusiera al descubierto y, luego, hacia finales del siglo XIX Nietzsche lo convirtiera en objeto de una reflexión radical. El caso es que la teoría del lenguaje del primer Romanticismo alemán, de la que hace ya tiempo se tomó buena nota en investigaciones monográficas ${ }^{86}$, nunca fue reconocida, sin embargo, como componente fundamental de la teoría romántica. Lo que había que contar sobre la teoría del lenguaje de ese periodo era lo que se buscaba en los escritos de Wilhelm von Humboldt. También la crítica del lenguaje de Nietzsche siguió alejada, en la mayoría de las interpretaciones, del centro de su filosofía. Desde luego que Fritz Mauthner, quien también a su vez era un prominente teórico del lenguaje, había constatado una conexión directa entre la crítica del lenguaje de Nietzsche y su crítica del conocimiento. En el ámbito de la moral, por ejemplo, Nietzsche habría partido de un análisis de las denominaciones tradicionales de ‘bueno' o ‘malo'. Sin embargo, Mauthner no tardó en criticar

${ }^{84}$ KSA III 114.

${ }^{85}$ Foucault, M., op. cit., p. 297.

${ }^{86}$ Cf. Fiesel, E., Die Sprachphilosophie der deutschen Romantik, Tubinga: Mohr Siebeck, 1927 (reeditado en Hildesheim-Nueva York: G. Olms, 1973); y Nüsse, H., Die Sprachtheorie 
la posición de Nietzsche como la de un «trompetero moral», esto es, la de un moralista que quiso establecer nuevas tablas de valores y, para ello, regresó a una credulidad en el lenguaje ${ }^{87}$. Otras interpretaciones posteriores, cuando se ocupan en general de la teoría nietzscheana del lenguaje, exponen su crítica del lenguaje como si se refiriera a principios más fundamentales, como la gramática, la razón o las funciones instintivas de la autoconservación, a los 'atavismos' y, por último, a las condiciones fisiológicas. El propio Nietzsche da la impresión de haber tenido ya a la vista una interpretación semejante, cuando por ejemplo escribe en el aforismo 20 de Más allá del bien y del mal: «el hechizo de determinadas funciones gramaticales es, en definitiva, el hechizo de juicios de valor fisiológicos y de condiciones raciales ${ }^{88}$. Las declaraciones de Nietzsche sobre el lenguaje parecían exigir un texto fundamentador para el hombre -un texto en el que representaran un papel protagonista el impulso instintivo, la crueldad y las técnicas de supervivencia. El aforismo 230 de Más allá del bien y del mal apunta en esa dirección. Según él, se trata prioritariamente de reconocer de nuevo «bajo ese color y esa capa de pintura halagadores [...] el terrible texto básico homo natura ${ }^{89}$; lo cual significa «Retraducir, en efecto, el hombre a la naturaleza; adueñarse de las numerosas, vanidosas e ilusas interpretaciones y significaciones secundarias que han sido garabateadas y pintadas hasta ahora sobre aquel eterno texto básico homo natura $\gg^{90}$.

Por lo que respecta al carácter enunciativo de los escritos de Nietzsche, considerando en particular sus constantes contradicciones, nadie se sirvió de principios de explicación lingüística, sino de principios cognitivos. La teoría empleada por la mayoría era la del perspectivismo, la de un constante cambio de perspectiva, que el propio Nietzsche puso de relieve en ciertos pasajes prominentes de sus escritos. Karl Jaspers, quien más a fondo ha estudiado el perspectivismo cognitivo de Nietzsche, habla de una «reflexión infinita», una «dialéctica total infinita» que anima los escritos de Nietzsche, que incorpora cada forma finita de la racionalidad en el proceso de esa reflexión infinita y que vuelve a poner en cuestión todas sus comprobaciones apodícticas mediante la consideración de nuevas posibilidades ${ }^{11}$.

Friedrich Schlegels, Heidelberg: C. Winter, 1962.

${ }^{87}$ Cf. Mauthner, F., Beiträge zu einer Kritik der Sprache, Stuttgart: Cotta, 1901-1902, vol. 1, pp. 366-369; así como, del mismo autor, «Ola Hansons Schriften», Deutschland. Wochenschrift für Kunst, Literatur, Wissenschaft und soziales Leben, 46 (1890), 753-755.

${ }^{88}$ KSA V 35 (MBM p. 42).

${ }^{89}$ KSA V 169 (MBM p. 180).

${ }^{90}$ Ibid.

${ }^{91}$ Véase Jaspers, K., Nietzsche. Einführung in das Verständnis seines Philosophierens, Berlin-Leipzig: Walter de Gruyter, 1936; y «Zu Nietzsches Bedeutung in der Geschichte der Philosophie», en Jaspers, K., Aneignung und Polemik. Gesammelte Reden und Aufsätze, ed. H. Sauer, Múnich: Piper, 1968; Vernunft und Existenz. Fünf Vorlesungen, Bremen: J. Storm, 1947 
A diferencia de este acceso a Nietzsche, predominante en la primera mitad de nuestro siglo ${ }^{92}$, en nuestra época ${ }^{93}$ el interés se ha desplazado decisivamente hacia su filosofía del lenguaje. Indagaciones acerca de su teoría y su crítica del lenguaje ocupan hoy el lugar de investigaciones sobre su teoría y su crítica del conocimiento. Sus ideas sobre el lenguaje sirven de explicación de la ambigüedad de sus enunciados y confirman que no se les puede adjudicar ninguna significación última. Esta tendencia de la interpretación nietzscheana actual es manifiesta en Las palabras y las cosas de Foucault. Derrida, por su parte, concentra sus escritos sobre Nietzsche no en el 'qué', sino en el 'cómo' de su expresión, en el estilo de Nietzsche, que Derrida no obstante designa en plural como Los estilos de Nietzsche ${ }^{94}$. Decisivamente influyente en este rumbo de la investigación fue la gran importancia que la retórica le concedió a la formación del discurso filosófico de Nietzsche. Philippe Lacou-Labarthe fue el primero en hacer este descubrimiento, mientras consideraba minuciosamente las lecciones basilenses de Nietzsche sobre la retórica griega y romana ${ }^{95}$. Paul de Man ha ampliado luego esta vía de acceso a Nietzsche, al investigar tropos y figuras retóricas en el texto de Nietzsche ${ }^{96}$. Este quehacer con Nietzsche fue significativamente influyente para el redescubrimiento de la teoría del lenguaje del primer Romanticismo alemán ${ }^{97}$. Refiriéndose a Nietzsche y Mallarmé, dice Foucault que ahora por fin sabemos de dónde provienen nuestras preguntas relativas al lenguaje: «Se hicieron posibles por el hecho de que a principios del siglo XIX, habiéndose separado la ley del discurso de la representación, el ser del lenguaje se encontró como fragmentado; pero se hicieron necesarias después de que, con Nietzsche, con Mallarmé, el pensamiento fue conducido de nuevo, y en forma violenta, hacia el lenguaje mismo, hacia su ser único y difícil. Toda la curiosidad de nuestro pensamiento se aloja ahora en la pregunta: ¿Qué es el lenguaje, cómo rodearlo para hacerlo aparecer en sí mismo y en su plenitud? $\gg^{98}$

traducción de Javier Rodríguez Fernández

(reed. en Múnich: Piper, 1973).

${ }^{92}$ Esto es, del siglo XX [Nota del traductor].

${ }^{93}$ Es decir, en la segunda mitad del mismo siglo XX [Nota del traductor].

${ }^{94}$ Derrida, J., Éperons. Les styles de Nietzsche, París: Flammarion, 1978 (Espolones. Los estilos de Nietzsche, tr. M. Arranz Lázaro, Valencia: Pre-Textos, 1981).

${ }_{95}$ Véase, más arriba, la nota número 50; así como Lacou-Labarthe, P. - Nancy, J.L. «Friedrich Nietzsche. Rhétorique et langage. Texts traduits, présentés et annotés», Poétique, 5 (1971), 53-76.

${ }^{96}$ Man, Paul de, Allegories of Reading. Figural Language in Rousseau, Nietzsche, Rilke, and Proust, New Haven-Londres: Yale University Press, 1976.

${ }^{97}$ De nuevo, véase el escrito de Lacou-Labarthe citado más arriba, en la nota número 50. 